\title{
Role of JTT-501, a new insulin sensitiser, in restoring impaired GLUT4 translocation in adipocytes of rats fed a high fat diet
}

\author{
J. Terasaki ${ }^{1}$, M. Anai ${ }^{1}$, M.Funaki ${ }^{2}$, T.Shibata ${ }^{3}$, K. Inukai ${ }^{1}$, T. Ogihara ${ }^{2}$, H. Ishihara ${ }^{2}$, H. Katagiri ${ }^{2}$, Y. Onishi ${ }^{2}$, \\ H.Sakoda ${ }^{2}$, Y.Fukushima ${ }^{2}$, Y. Yazaki ${ }^{2}$, M.Kikuchi ${ }^{1}$, Y. Oka ${ }^{4}$, T. Asano ${ }^{2}$ \\ ${ }^{1}$ Institute for Adult Diseases, Asahi Life Foundation, Tokyo, Japan \\ ${ }^{2}$ Third Department of Internal Medicine, Faculty of Medicine, University of Tokyo, Tokyo, Japan \\ ${ }^{3}$ Japan Tobacco Inc, Central Pharmaceutical Research Institute, Osaka, Japan \\ ${ }^{4}$ Third Department of Internal Medicine, Yamaguchi University School of Medicine, Yamaguchi, Japan
}

\begin{abstract}
Summary JTT-501 is an insulin-sensitising compound with an isoxazolidinedione rather than a thiazolidionedione structure. Sprague-Dawley rats fed a high fat diet for 2 weeks were used as an animal model of insulin resistance, and JTT-501 was administered for the final week of the diet. An euglycaemic glucose clamp study showed that the glucose infusion rate (GIR) required to maintain euglycaemia was $57 \%$ lower in rats fed a high fat diet than in control rats, and that JTT-501 treatment restored the reduction in GIR produced by the high fat diet. To explain the mechanisms underlying the effects of a high fat diet and JTT-501 treatment, epididymal fat pads were excised and used in the analysis of insulin action. The high fat diet caused: (1) a $58 \%$ decrease in insulin receptor substrate-1 (IRS-1) content with a $58 \%$ decrease in IRS-1 tyrosine phosphorylation; (2) reductions of $56 \%$ and $73 \%$ respectively in insulin-induced maximal PI 3-kinase activation in anti-phosphotyrosine and anti-IRS-1 antibody immunoprecipitates; (3) a $46 \%$ reduction in the glucose transporter protein,
\end{abstract}

GLUT4 content and, consequently, (4) severely impaired insulin-induced GLUT4 translocation to the plasma membrane and glucose uptake in adipocytes. JTT-501 treatment restored appreciably the protein content and tyrosine phosphorylation level of IRS-1. Insulin-stimulated PI 3-kinase activation was also restored in anti-phosphotyrosine and anti-IRS-1 antibody immunoprecipitates. As reflected by these improvements in insulin signalling, JTT-501 treatment improved considerably insulin-induced GLUT4 translocation to the plasma membrane as well as insulin-induced glucose uptake. However, JTT-501 had no effect on the decrease in GLUT4 content produced by the high fat diet. These observations suggest that JTT-501 enhances insulin signalling and may be effective in reducing insulin resistance. [Diabetologia (1998) 41: 400-409]

Keywords Insulin sensitiser, isoxazolidinedione, JTT501, GLUT4, phosphatidylinositol 3-kinase, high fat diet, adipocyte.
Insulin resistance is an important factor in the pathogenesis of non-insulin-dependent diabetes mellitus (NIDDM) [1-4]. Several oral hypoglycaemic drugs

Received: 23 June 1997 and in revised form: 29 November 1997

Corresponding author: Dr. T.Asano, Third Department of Internal Medicine, Faculty of Medicine, University of Tokyo, 7-3-1, Hongo, Bunkyo-ku, Tokyo, 113, Japan

Abbreviations: NIDDM, Non-insulin-dependent diabetes mellitus; PI 3-kinase, phosphatidylinositol 3-kinase; TBS, Tris-buffered saline; SDS, sodium dodecyl sulphate; PMSF, phenylmethylsulfonyl fluoride; Hepes, 4-(2-hydroxyethyl)-1-piperazineethanesulphonic acid; IRS-1, insulin receptor substrate-1; PPAR- $\gamma$, peroxisome proliferator-activated receptor $\gamma$. are now available to treat NIDDM. Thiazolidionedione and its derivatives are a new class of compounds that seem to work by enhancing insulin action without stimulating beta cell insulin secretion [5]. JTT-501, the drug used in this study is an isoxazolidinedione compound that is structurally different from thiazolidionedione compounds (Fig.1), and was developed to treat NIDDM. This agent binds to peroxisome proliferator-activated receptor $\gamma(\operatorname{PPAR}-\gamma)$ and enhances the differentiation of 3T3-L1 cells into adipocytes, in a manner similar to that reported for thiazolidionedione and its derivatives [6, 7]. In addition, oral JTT-501 has been shown to improve considerably insulin sensitivity in diabetic KK-Ay mice and 


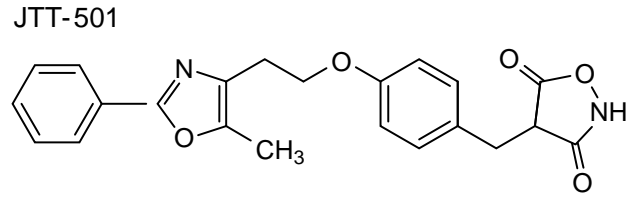

Fig. 1. Chemical structure of JTT-501

in Zucker fatty and Zucker diabetic rats, based on fasting plasma glucose and insulin concentrations as well as glucose tolerance test results (unpublished observations). Thus, JTT-501 is a promising insulin sensitising agent that may be very potent.

In muscle and adipose tissue, GLUT4 glucose transporter capacity on the cell surface seems to be rate-limiting for glucose utilisation. GLUT4 resides in intracellular pools in the basal condition, and is recruited to the plasma membrane in response to insulin stimulation $[8,9]$. Defects in the regulation of both GLUT4 synthesis and translocation could, therefore, be major factors in the reduced glucose uptake seen in insulin resistance. It has also been suggested that low insulin-stimulated glucose transport rates in adipocytes from patients with NIDDM do not result from a defect in the insulin receptor, but from a change in a postreceptor site [10-12]. A recent series of reports has shown that the activation of phosphatidylinositol 3-kinase (PI 3-kinase) is necessary for the translocation of GLUT4 to the plasma membrane [13-18] and that this process is impaired in various rodent models of diabetes [19-23].

In this study, JTT-501 treatment reversed the insulin resistance induced in rats by a high fat diet. The pharmacological effect of JTT-501 on the impaired glucose transport system in adipose cells produced by a high fat diet was also assessed. Here the focus was on the expression level and insulin regulated translocation of GLUT4, and on insulin signalling that leads to the activation of PI 3-kinase, which is thought to be linked to the translocation of GLUT4 to the plasma membrane.

\section{Materials and methods}

Animals. Male Sprague-Dawley rats were obtained from Nisseizai, Tokyo, Japan at 5 weeks of age. They were divided into three groups and fed one of the following diets for 2 weeks: (1) normal chow diet (protein $23 \%$, lipid $11 \%$, and carbohydrate $66 \%$ of total calories) (2) diet high in fat (protein $24.5 \%$, lipid $60 \%$, and carbohydrate $15.5 \%$ of total calories), or (3) high fat diet for 2 weeks plus JTT-501 $100 \mathrm{mg} / \mathrm{kg}$ once a day for the last week. The high fat diet was formulated to assure that $60 \%$ of total calories came from lard. JTT-501 was suspended in $0.5 \%$ carboxymethylcellulose sodium and administered orally by gavage.

Euglycaemic hyperinsulinaemic clamp. To assess insulin sensitivity, euglycaemic hyperinsulinaemic clamp studies were performed. Rats were anaesthetized with nembutal $(50 \mathrm{mg} / \mathrm{kg})$.
A catheter was inserted in the right jugular vein for insulin and glucose infusion, and a catheter in the left carotid artery was used for blood sampling. Regular human insulin (14 $\mathrm{mU} \cdot \mathrm{min}^{-1} \cdot \mathrm{kg}^{-1}$, Novolin-U, Novo-Nordisk, Copenhagen, Denmark) was infused intravenously, and whole blood glucose concentrations were determined at 5 minute intervals with a Mediace GR-100 (Telmo). A 10\% dextrose solution was infused at a rate that allowed maintenance of the blood glucose concentration at $6.7 \mathrm{mmol} / \mathrm{l}$.

Preparation of isolated adipocytes. All the rats were killed by decapitation, and were not fasted before hand. Epididymal fat pads were excised. The fat pads were digested with collagenase $(1 \mathrm{mg} / \mathrm{ml})$, and the isolated adipocytes obtained were suspended in Krebs-Ringer-biocarbonate (KRB) buffer supplemented with $30 \mathrm{mmol} / \mathrm{l}$ Hepes, $1 \%$ bovine albumin (fraction $\mathrm{V}$ ), $3 \mathrm{mmol} / \mathrm{l}$ glucose, and $200 \mathrm{mmol} / \mathrm{l}$ adenosine at $\mathrm{pH} 7.4$ as described by Honnor et al. [24]. Adipocytes were washed three times with the same buffer and resuspended to a cell density consistent with a $25 \%$ adipocrit.

Determination of GLUT4 translocation from intracellular pools to plasma membrane. Subcellular membrane fractions were prepared by differential centrifugation from homogenised fat cells as described by McKeel and Jarett [25] and Cushman and Wardzala [8] with some modifications [26]. The fat cell homogenates were centrifuged at $3000 \mathrm{~g}$ for $15 \mathrm{~min}$ to sediment the plasma membrane fraction. The fat cakes were discarded, and the intranatant was centrifuged at $12000 \mathrm{~g}$ for 15 min to sediment the plasma membrane fraction. The supernatant was centrifuged at $28000 \mathrm{~g}$ for $15 \mathrm{~min}$, and the resulting supernatant was centrifuged at $146000 \mathrm{~g}$ for $75 \mathrm{~min}$, yielding a particulate fraction termed low density microsomes [8].

Determination of GLUT4 content. Total adipose tissue membranes were obtained by centrifuging the cell homogenates at $146000 \mathrm{~g}$ for $75 \mathrm{~min}$. Altogether $50 \mu \mathrm{g}$ of protein in the total membrane, plasma membrane, and low density microsome fractions were separated by SDS-polyacrylamide gel electrophoresis and transferred to nitrocellulose filters. The filters were blocked with $3 \%$ powdered skim milk in Tris-buffered saline (TBS), pH 7.4, overnight at $4{ }^{\circ} \mathrm{C}$, and incubated for $3 \mathrm{~h}$ at room temperature with antiserum to the $\mathrm{C}$-terminus of GLUT4 [27]. After three washings with TBS, the bound immunoglobulins were probed with ${ }^{125}$ I-labelled protein A, and the ${ }^{125}$ I-labelled GLUT4-associated signal was quantified with a Molecular Imager GS-525 using Screen-CS.

Immunoprecipitation and Western blotting. The proteins were made soluble in buffer composed of $50 \mathrm{mmol} / \mathrm{l}$ Hepes (pH 7.0), $150 \mathrm{mmol} / \mathrm{l} \mathrm{NaCl}, 1 \mathrm{mmol} / \mathrm{l}$ EGTA, $100 \mathrm{mmol} / \mathrm{l}$ sodium fluoride, $10 \mathrm{mmol} / 1$ sodium pyrophosphate, $1 \%$ Triton $\mathrm{X}-100,10 \%$ glycerol, $1.5 \mathrm{mmol} / \mathrm{l} \mathrm{MgCl}_{2}, 1 \mathrm{mmol} / 1$ sodium orthovanadate, $1 \mathrm{mmol} / \mathrm{l}$ phenymethylsulfonyl fluoride (PMSF), and $0.1 \mathrm{mg} / \mathrm{ml}$ aprotinin. After centrifugation at $15000 \mathrm{~g}$ at $4{ }^{\circ} \mathrm{C}$ for $30 \mathrm{~min}$ to remove insoluble material, the supernatants were used for immunoprecipitation. The supernatants containing equal amounts of protein $(3 \mathrm{mg} / 1 \mathrm{ml}$ for each tube) were incubated with anti-IRS-1 antibody $(10 \mathrm{mg} / \mathrm{ml})$, anti-phosphotyrosine antibody (4G10) $(5 \mathrm{mg} / \mathrm{ml})$, anti-p85 $\alpha$ antibody (UBI), or anti-p110 $\beta$ antibody $(10 \mathrm{mg} / \mathrm{ml})$, and then incubated with $10 \mu \mathrm{l}$ of protein A-Sepharose beads. The samples were washed five times with the same buffer and boiled in Laemmli sample buffer containing $100 \mathrm{mmol} / \mathrm{l}$ dithiothreitol. The immunoprecipitated samples were subjected to SDSPAGE and the immunoblotting using each antibody was performed with enhanced chemiluminescence (ECL) according 
Table 1. Body weight before and after 2 weeks study; four groups of rats

\begin{tabular}{lcccc}
\hline & Chow diet & Chow diet + JTT-501 & High fat diet & High fat diet + JTT-501 \\
\hline Body weight & & & & \\
$\quad$ Initial $(\mathrm{g})$ & $141.1 \pm 1.3$ & $140.2 \pm 1.7$ & $139.6 \pm 1.6$ & $138.1 \pm 1.6$ \\
$\quad 14 \mathrm{~d}(\mathrm{~g})$ & $233.4 \pm 2.3$ & $238.7 \pm 3.9$ & $242.9 \pm 4.9$ & $242.9 \pm 3.7$ \\
Food intake per rat $\left(\mathrm{kcal}^{-1} \cdot \mathrm{d}^{-1}\right)$ & $83.2 \pm 1.6$ & $83.6 \pm 3.5$ & $82.5 \pm 2.4$ & $82.6 \pm 1.3$ \\
\hline
\end{tabular}

Mean $\pm \operatorname{SEM}(n=20)$

Table 2. Serum biochemical parameters of three groups of rats

\begin{tabular}{lccl}
\hline & Chow diet & High fat diet & $\begin{array}{l}\text { High fat diet }+ \\
\text { JTT-501 }\end{array}$ \\
\hline Glucose (mmol/l) & $2.91 \pm 0.24$ & $4.60 \pm 0.20^{\mathrm{b}}$ & $4.15 \pm 0.29^{\mathrm{a}}$ \\
Insulin (pmol/l) & $78 \pm 5$ & $137 \pm 22^{\mathrm{a}}$ & $118 \pm 14$ \\
Triglyceride (mg/dl) & $28.9 \pm 3.4$ & $51.3 \pm 9.8^{\mathrm{c}}$ & $21.5 \pm 1.4^{\mathrm{d}}$ \\
\hline
\end{tabular}

Values are means $\pm \operatorname{SEM}(n=10)$.

${ }^{\mathrm{a}} p<0.01,{ }^{\mathrm{b}} p<0.001 v$ chow diet, ${ }^{\mathrm{c}} p<0.05 v$ chow diet,

${ }^{\mathrm{d}} p<0.01 v$ high fat diet

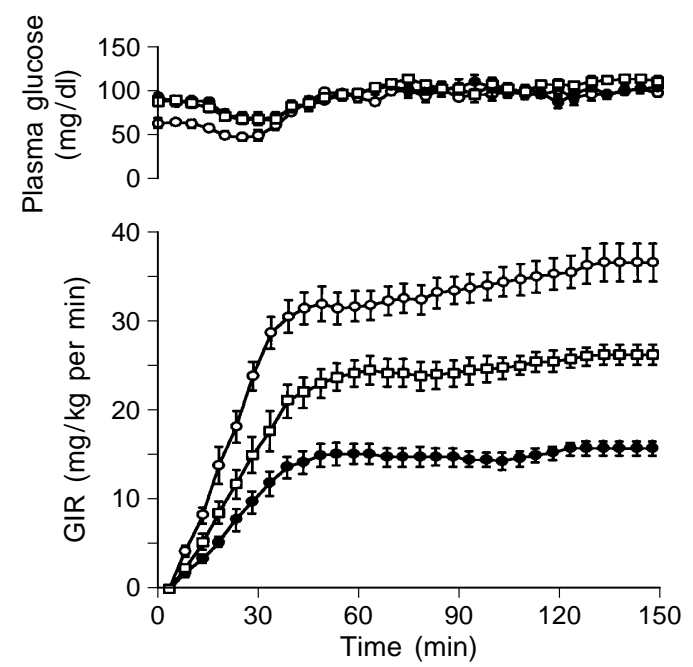

Fig. 2. Effect of JTT-501 on in vivo insulin action in rats fed a high fat diet. Sprague-Dawley rats (5 weeks old) were fed a high fat diet for 2 weeks. JTT-501 (100 mg/kg per day) was given orally during the second week. After the last dose of JTT501, rats were fasted overnight. The glucose infusion rate (GIR) required to maintain euglycaemia during a glucose clamp study at an insulin infusion rate of $14 \mathrm{mU} \cdot \mathrm{min}^{-1} \cdot \mathrm{kg}^{-1}$ was measured. Control diet $(0)$, high fat diet $(\bullet)$, high fat diet plus JTT-501 $(\square)$. Values are means $\pm \operatorname{SEM}(n=6)$

to the manufacturer's instructions. The band intensities were quantitated with a Molecular Imager GS-525 using ScreenHC.

PI 3-kinase assay. After stimulation with various concentrations of insulin for $10 \mathrm{~min}$, adipocytes were immediately homogenised in 10 volumes of ice cold buffer composed of $50 \mathrm{mmol} / \mathrm{l} \mathrm{Hepes} \mathrm{(pH} \mathrm{7.5),} 137 \mathrm{mmol} / \mathrm{l} \mathrm{NaCl}, 1 \mathrm{mmol} / 1 \mathrm{MgCl}_{2}$, $1 \mathrm{mmol} / \mathrm{l} \mathrm{CaCl}_{2}, 2 \mathrm{mmol} / 1 \mathrm{Na}_{2} \mathrm{VO}_{4}, 10 \mathrm{mmol} / 1$ sodium pyrophosphate, $10 \mathrm{mmol} / \mathrm{l} \mathrm{NaF}, 2 \mathrm{mmol} / \mathrm{l}$ EDTA, $1 \% \mathrm{NP}-40,10 \%$ glycerol, $2 \mu \mathrm{g} / \mathrm{ml}$ aprotinin, $10 \mu \mathrm{g} / \mathrm{ml}$ antipain, $5 \mu \mathrm{g} / \mathrm{ml}$ leupeptin, $0.5 \mu \mathrm{g} / \mathrm{ml}$ pepstatin, $1.5 \mu \mathrm{g} / \mathrm{ml}$ benzamidine, and $34 \mu \mathrm{g} / \mathrm{ml}$ PMSF. The insoluble materials were removed by centrifuga- tion at $15000 \mathrm{~g}$ for $30 \mathrm{~min}$ at $4{ }^{\circ} \mathrm{C}$, and the supernatants were immunoprecipitated with anti-IRS-1 or anti-phosphotyrosine antibody. The PI 3-kinase activities in the immunoprecipitates were measured as previously described [28].

Glucose uptake studies. Isolated adipocytes $\left(2 \times 10^{5}\right.$ cells $\left./ \mathrm{ml}\right)$ were suspended in KRB buffer containing bovine serum albumin $(10 \mathrm{mg} / \mathrm{ml}, \mathrm{pH} 7.4)$ and preincubated with or without insulin for $15 \mathrm{~min}$ at $37^{\circ} \mathrm{C}$. Glucose uptake was initiated by the addition of 2 -deoxy-[1-3 $\left.{ }^{3} \mathrm{H}\right]-\mathrm{D}$-glucose at a concentration of $0.1 \mathrm{mmol} /(0.25 \mu \mathrm{Ci})$. The assay was terminated after a 3 min incubation by transferring $200 \mu \mathrm{l}$ aliqots from the assay mixture into plastic microcentrifuge tubes containing $100 \mu \mathrm{l}$ of dinonyl phthalate and centrifuging rapidly. Incubation was considered ended the instant that centrifuging began. The amount of 2-deoxyglucose trapped in the extracellular water space of the cell layers was determined with $\left[\mathrm{U}_{-}{ }^{14} \mathrm{C}\right]-$ sucrose and corrected as described in [29]. In each experiment, the uptake of 2-deoxyglucose at each point represents the mean of two separate experiments of triplicate determinations.

\section{Results}

Effects of diet and JTT-501 treatment on body weight and glucose, insulin, and lipid concentrations. Characteristics of the experimental animals after 2 weeks of treatment are presented in Tables 1 and 2. Neither the high fat diet nor JTT-501 treatment increased the body weight. The fasting plasma glucose and insulin concentrations were significantly higher in rats fed the high fat diet than in control rats, suggesting insulin resistance. In addition, plasma triglyceride concentrations in rats fed the high fat diet were $75 \%$ higher than those in control rats.

JTT-501 treatment for one week reduced fasting plasma glucose and insulin concentrations and returned raised plasma triglyceride concentrations to normal compared with the high fat diet alone.

Euglycaemic-hyperinsulinaemic clamp. During the steady state from 60 to $150 \mathrm{~min}$, glucose values were clamped at euglycaemic levels (Fig. $2 \mathbf{A}$ ). With the infusion of insulin $\left(14 \mathrm{mU} \cdot \mathrm{min}^{-1} \cdot \mathrm{kg}^{-1}\right)$, the GIR was considerably lower in rats fed a high fat diet than in control rats $(56.9 \%)$. The reduced GIR induced by the high fat diet was partly reversed by JTT-501 treatment, but was still $28.0 \%$ lower in the treated rats than in control rats (Fig. $2 \mathbf{B}$ ). 
A
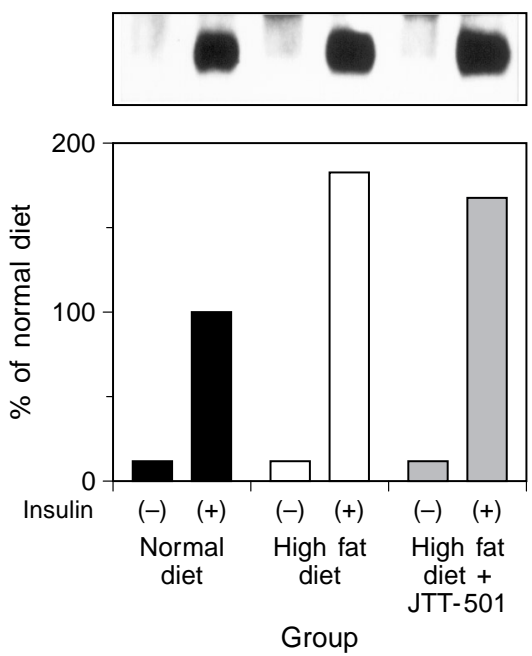

B
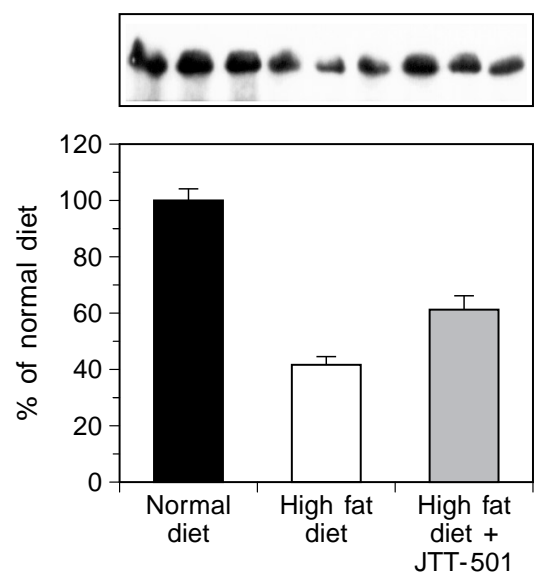

Group
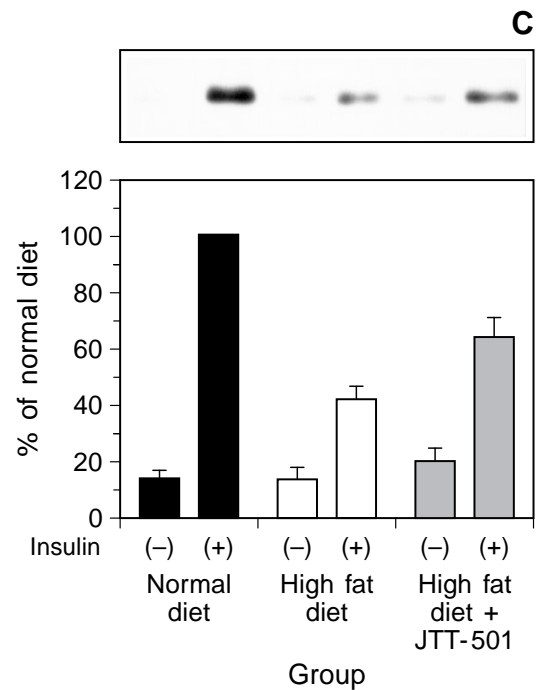

Fig.3 A-C. Effects of a high fat diet and JTT-501 on tyrosine phosphorylation of the insulin receptor (A), and on the expression (B) and tyrosine phosphorylation (C) of IRS-1. Isolated adipocytes were incubated in the presence or absence of $10^{-7} \mathrm{M}$ insulin for $10 \mathrm{~min}$ at $37^{\circ} \mathrm{C}$. Upper panel $\mathbf{A}$ the tyrosine phosphorylation level of the insulin receptor was determined by immunoprecipitation followed by immunoblotting with the antibody against phosphotyrosine. Upper panels $\mathbf{B}$ and $\mathbf{C}$ the cell lysates were immunoprecipitated with antibodies against phosphotyrosine and IRS-1, respectively. The amount and tyrosine phosphorylation level of IRS-1 were determined by immunoblotting the immunoprecipitates with the antibodies against IRS- 1 and phosphotyrosine, respectively. Lower panels $\mathbf{A}, \mathbf{B}$ and $\mathbf{C}$ : the band intensities were quantified using a Molecular Imager GS-525. For $\mathbf{A}$, independent experiments were performed three times and yielded similar results. A representative experiment is shown. In panel $\mathbf{B}$, the bars represent the mean \pm SE of two independent experiments performed in triplicate. High fat diet vs high fat diet plus JTT-501, $p<0.01$. In panel $\mathbf{C}$, the bars represent the mean \pm SEM of four independent experiments. High fat diet vs high fat diet plus JTT-501, $p<0.05$. Values are expressed in relative units, and values of $100 \%$ are ascribed to insulin-induced tyrosine phosphorylation of the insulin receptor (A), the amount of IRS-1 (B), and the insulin-induced tyrosine phosphorylation of IRS-1 (C) in adipocytes from rats fed a normal diet

Effects of diet and JTT-501 treatment on autophosphorylation of adipocyte insulin receptors. As shown in Fig. $3 \mathbf{A}$, the insulin-induced autophosphorylation of insulin receptors on adipocytes from rats fed the high fat diet was $78 \%$ higher than that on adipocytes from control rats. The JTT-501 treatment reduced by approximately $7 \%$ the increased insulin receptor autophosphorylation associated with the high fat diet.

Effects of diet and JTT-501 treatment on IRS-1 protein and tyrosine phosphorylation of IRS-1. The amount of IRS-1 protein was determined by immunoprecipitation, which was followed by immunoblotting with the antibody against IRS- 1 . The amount of IRS- 1 in adipocytes of rats fed a high fat diet for 2 weeks was $42 \%$ of the level in control animals. JTT-501 treatment for the final week reversed this decrease in IRS- 1 protein to $62 \%$ of the amount of IRS- 1 in adipocytes from rats fed the control diet (Fig. $3 \mathbf{B}$ ).

The tyrosine phosphorylation level of IRS-1 was determined by immunoblotting the IRS- 1 antibody immunoprecipitates with the phosphotyrosine antibody. As shown in Figure $3 \mathbf{C}$, the tyrosine phosphorylation of IRS-1 in adipocytes from rats on the high fat diet was also reduced to $42 \%$ of the value in control rats. This decrease in IRS-1 phosphorylation with the high fat diet was partly reversed by JTT-501 treatment.

Effects of diet and JTT-501 treatment on insulin-induced PI 3-kinase activation. The effects of a high fat diet and JTT-501 treatment on insulin-induced PI 3kinase activation were investigated (Fig. 4). In adipocytes from control rats, the antibody to phosphotyrosine showed a dramatic increase in PI 3-kinase activity in accordance with an increasing insulin concentration. In contrast, this insulin-induced increase in PI 3-kinase activity associated with tyrosine-phosphorylated protein(s) was noticeably attenuated in adipocytes from rats fed the high fat diet $(56 \%$ decrease at $10^{-7}$ mol insulin in comparison with the control diet). The 1-week JTT-501 treatment reduced the impairment of PI 3-kinase activity, associated with tyrosine-phosphorylated protein(s), induced by the high fat diet (Fig. 4 A).

Assay of the PI 3-kinase activity in the immunoprecipitates obtained with the antibody against IRS1 yielded similar results. The high fat diet reduced considerably the association of PI 3-kinase activity with tyrosine phosphorylated IRS-1, and this reduction was shown to be partly reversed by the JTT-501 treatment (Fig. 4 B).

Effects of diet and JTT-501 treatment on GLUT4 content. The amount of GLUT4 protein in adipocytes 

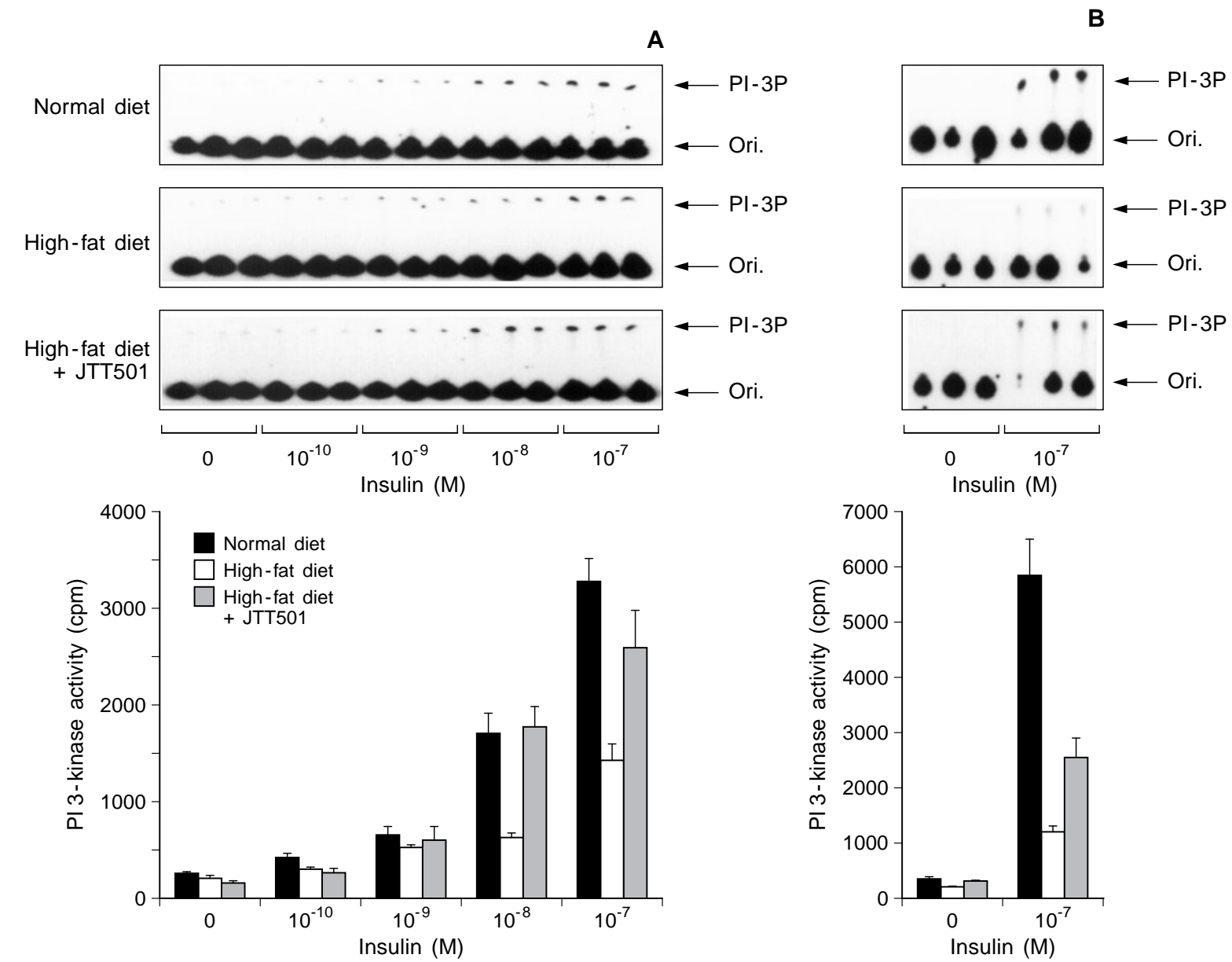

Fig.4 A, B. Effects of high fat diet and JTT-501 treatment on the activation of PI 3-kinase in phosphotyrosine antibody (A) and IRS-1 antibody (B) immunoprecipitates. Upper panels: Isolated adipocytes were incubated in the absence or presence of the indicated concentrations of insulin for $10 \mathrm{~min}$ at $37^{\circ} \mathrm{C}$. The cell lysates were immunoprecipitated with antibodies against phosphotyrosine or IRS-1. The PI 3-kinase activities were measured as described in Materials and Methods. Lower panels: The radioactivities incorporated into PI-3P were quantified using a Molecular Imager GS-525. Data are shown as means \pm SEM of experiments performed in triplicate. The three experiments yielded similar results. (A) High fat diet vs high fat diet plus JTT-501 at $10^{-8} \mathrm{M}$ insulin, $p<0.05$. (B) High fat diet vs high fat diet plus JTT-501 at $10^{-7} \mathrm{M}$ insulin, $p<0.05$

were determined by immunoblotting the total membrane fraction with the specific antibody against GLUT4. As shown in Figure $5 \mathbf{A}$, the amounts of GLUT4 in adipocytes from rats fed the high fat diet were only $54 \%$ of control diet values. JTT-501 had no effect on the down-regulation of GLUT4 induced by the high fat diet.

Effects of diet and JTT-501 treatment on GLUT4 translocation from intracellular pools to the plasma membrane. Insulin stimulation of adipocytes from rats fed a normal diet induces dramatic recruitment of GLUT4 from intracellular pools to the plasma membrane, resulting in an insulin-induced increase in glucose uptake. The GLUT4 increases in the plasma membrane in the presence compared with the absence of insulin were: 5.8 fold in adipocytes from rats fed a normal diet, 0.7 fold in those on the high fat diet and 2.6 fold in rats fed the high fat diet but treated with JTT-501 for the final week (Fig. 5 B, left two bars in each box). A similar insulin-stimulated translocation of GLUT4 was observed in the amount of GLUT4 in the intracellular pools (Fig. 5 B, right two bars in each box). These results show that JTT-501 reversed considerably the impaired GLUT4 translocation induced by the high fat diet.

Effect of diet and JTT-501 treatment on glucose uptake. Figure 6 presents basal and insulin stimulated 2-deoxyglucose uptake in adipocytes obtained from each group of rats. The 2-deoxyglucose uptake in the adipocytes from rats fed a high fat diet in the basal and insulin-stimulated conditions were reduced by $22 \%$ and $51 \%$ respectively compared with control rats. JTT-501 increased the basal glucose uptake by $113 \%$ and insulin stimulated 2-deoxyglucose uptake by $83 \%$ compared with rats fed a high fat diet. These results indicated that JTT-501 treatment resolved al- 
A
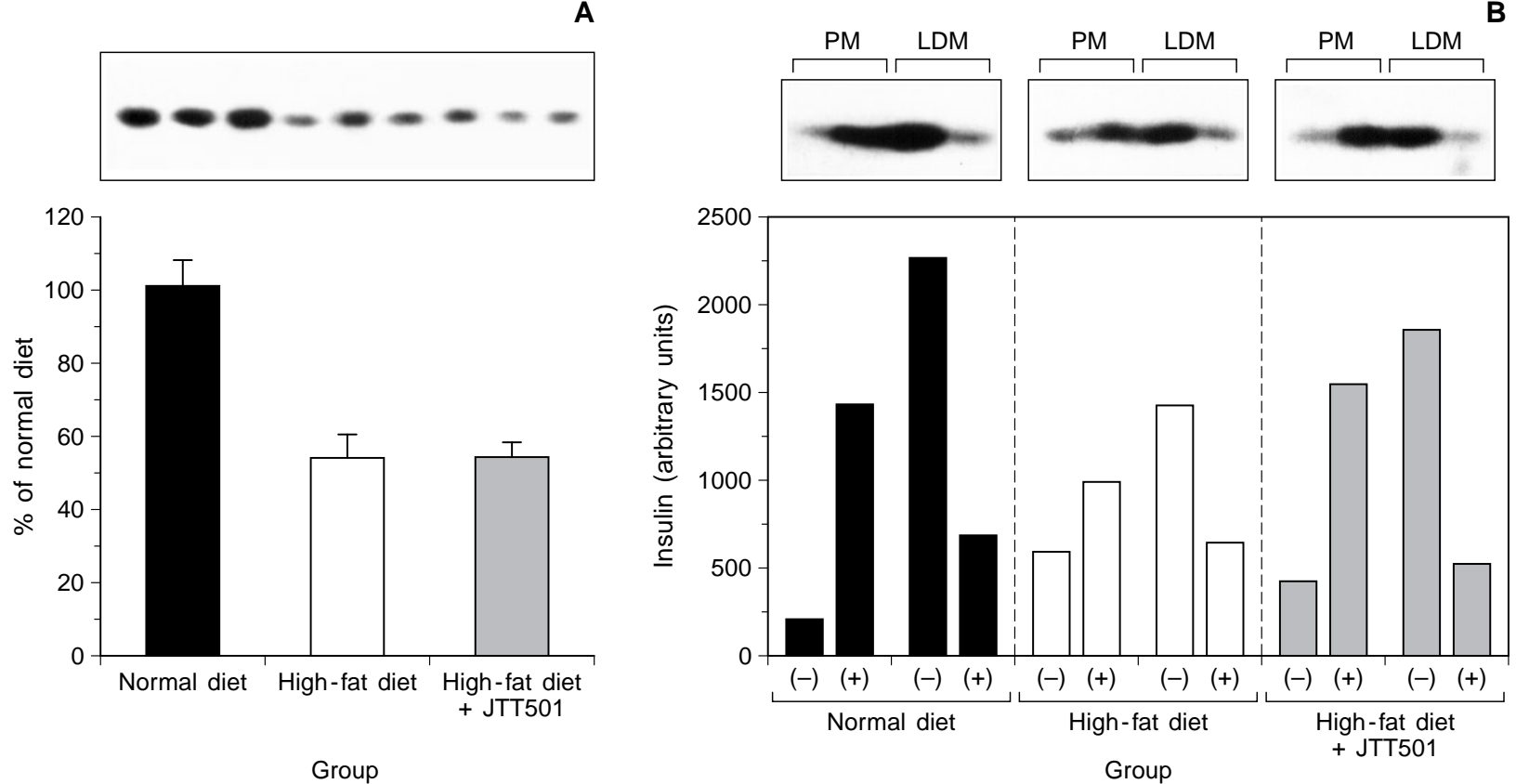

Fig. 5. Effects of a high fat diet and JTT-501 treatment on the expression (A) and insulin-induced translocation to the cell surface (B) of the GLUT4 glucose transporter. Upper panels: Isolated adipocytes were incubated in the presence or absence of $10^{-7} \mathrm{M}$ insulin for $10 \mathrm{~min}$ at $37^{\circ} \mathrm{C}$. Cells were homogenised and subcellular fractionation was performed as described in Materials and Methods. Altogether $50 \mu \mathrm{g}$ of total membrane protein, the plasma membrane fraction (PM) and the low density microsome fraction (LDM) were separated by SDSPAGE, and the amount of GLUT4 in each fraction was determined by immunoblotting using the antibody against the C-terminus of GLUT4. Lower panels: The band intensities were quantified using a Molecular Imager GS-525. For panel A, the bars represent the mean \pm SEM. Values are expressed in relative units, with a value of $100 \%$ ascribed to the content of GLUT4 protein in adipocytes from rats fed a normal diet. One way ANOVA with Turky's multiple comparison test showed significant differences: Control vs high fat diet, $p<0.05$; control vs high fat diet plus JTT-501, $p<0.05$. For panel $\mathbf{B}$, the experiments were performed three times yielding similar results, and representative data are shown

most completely the impaired insulin-stimulated glucose uptake in adipose tissue that was induced in rats on a high fat diet.

\section{Discussion}

Insulin resistance in NIDDM is thought to result in many cases from a postreceptor defect in insulin signalling in peripheral tissues. Although the mechanism by which this defect develops is only beginning to be understood, many studies have shown that obesity, a high fat diet, stress, and insufficient exercise lead to insulin resistance [30-38]. We investigated

the mechanism of adipocyte insulin resistance induced by a high fat diet, focussing on the expression level and translocation of GLUT4, as well as on the insulin signalling that leads to the activation of PI 3kinase - thought to be involved in the translocation of GLUT4 to the plasma membrane. Furthermore, we evaluated the effect of JTT-501, a new insulin sensitiser, on factors that are impaired by feeding a high fat diet.

Insulin receptor kinase activity was high in adipocytes of rats fed a high fat diet in this study, agreeing with the findings of a previous report [39]. Thus, insulin receptor kinase impairment is unlikely to be involved in the occurrence of insulin resistance in fat cells. However, insulin receptor tyrosine kinase activity, reported to be considerably lower than that in adipose tissues [39], is associated with insulin resistance in skeletal muscle and the liver of rats fed a high fat diet. Two possible mechanisms by which a high fat diet induces insulin resistance in adipocytes were suggested by our findings. One is the down-regulation of IRS-1 protein, reported previously [40, 41], which reduces the tyrosine phosphorylation level of IRS-1. We showed noticeable impairment of PI 3-kinase activation in IRS-1 antibody immunoprecipitates and in phosphotyrosine antibody immunoprecipitates in adipocytes of rats fed a high fat diet. Studies have shown that the activation of PI 3-kinase is necessary for insulin-induced glucose transporter translocation to the plasma membrane in muscle and fat cells that results in an increase in glucose uptake [13-18]. For example, this process has been shown to be blocked by specific inhibitors of PI 3-kinase, such as wortmannin [13] and LY294002 [14], as well as by the overexpression or microinjection of the dominant negative mutant $\mathrm{p} 85 \alpha[15,16]$. In contrast, overexpression of 


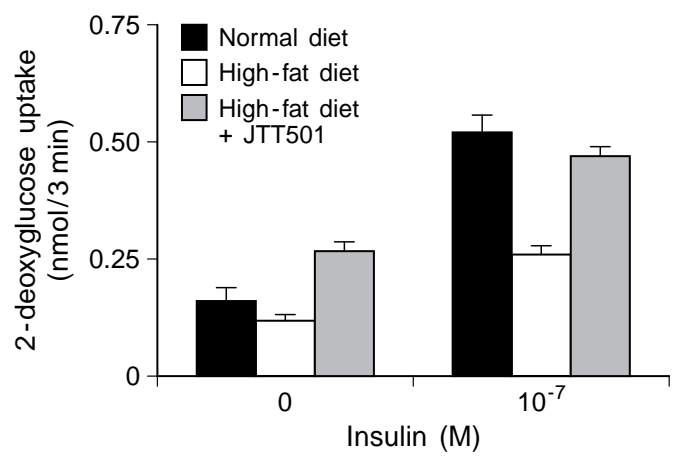

Fig. 6. Effect of JTT-501 on 2-deoxyglucose uptake of isolated adipocytes. Adipocytes from rats fed a control, high fat, or high fat diet plus JTT-501 were preincubated for $45 \mathrm{~min}$, then the uptake of 2-deoxyglucose was measured following 3-min incubation as indicated in the text. Data represent the mean \pm SEM. One way ANOVA with Turky's multiple comparison test showed significant differences: Control vs high fat diet, $p<0.001$; high fat vs high fat diet plus JTT-501, $p<0.01$

wild-type or constitutive active p110 in 3T3-LI cells induces glucose transporter translocation to the plasma membrane, irrespective of insulin stimulation $[17,18]$. The PI 3-kinase activation defect in adipocytes may, therefore, be attributable to impaired GLUT4 translocation in response to insulin stimulation. We observed that GLUT4 translocation and 2deoxyglucose uptake do not occur efficiently in adipocytes from rats on a high fat diet compared with rats fed a control diet. These findings indicate that impaired PI 3-kinase activation in adipocytes from rats fed a high fat diet is a major cause of defective insulin-induced GLUT4 translocation to the plasma membrane and resultant glucose uptake.

The other defect in adipocytes from rats fed a high fat diet was a downregulation of GLUT4 protein, which was also reported previously [42]. Although it remains unclear how the expression of GLUT4 is regulated by various hormones and nutrients, many investigators, including our group, have speculated that a GLUT4 protein deficiency would decrease the extent of the insulin-induced increase in glucose uptake into cells [43-46].

We investigated the mechanism by which JTT-501 improves insulin sensitivity in adipocytes from rats fed a high fat diet. As mentioned in the Introduction, JTT-501 has an isoxazolidinedione structure (rather than the thiazolidionedione structure of members of the glitazone family, such as ciglitazone, troglitazone, pioglitazone and englitazone), and was shown by means of a euglycaemic clamp study and 2-deoxyglucose uptake to restore the insulin resistance induced by a high fat diet (Fig.2). Recent studies have shown that these compounds are potent and selective activators of peroxisome proliferator-activated receptor $\gamma($ PPAR $-\gamma)$, a member of the nuclear receptor superfamily that functions in adipogenesis [47-50]. JTT-501 also binds to PPAR- $\gamma(\mathrm{Kd} / \mathrm{Ki}$ in the binding assay experiments using GST-PPAR- $\gamma$ and $\left[{ }^{3} \mathrm{H}\right]-$ BRL49653; BRL49653: $1.4 \times 10^{-7} \mathrm{~mol}$, JTT-501: $3.3 \times 10^{-6} \mathrm{~mol}$ ), and incubation with JTT-501 was observed to induce the differentiation of 3T3-L1 cells into adipocytes (unpublished data). Although these receptors seem to function not only in adipocytes but also other insulin sensitive tissues such as muscle and liver, the evidence that PPAR $\gamma$ is expressed mainly in adipocytes suggests that adipocytes are the tissue most sensitive to thiazolidionedione or its derivatives, as well as the isoxazolidinedione derivative JTT-501. Because of this we used adipocytes to examine the mechanism by which JTT-501 restores insulin sensitivity. Our results suggest that JTT-501 treatment increases the amount and tyrosine phosphorylation level of IRS-1, although return to normal was partial. These changes appear to result in reversal of the impaired activation of PI 3-kinase. Englitazone, which belongs to the thiazolidionedione class of insulin sensitizing agents, reportedly prevented the insulin resistance associated with a high fat diet. Its mechanism of action, however, does not involve activation of the insulin signalling pathway via PI 3-kinase [40]. We have no explanation for this difference in the results of the study of Stephenson et al. from those of our study using JTT-501.

To date, many reports have examined the mechanisms of action of insulin-sensitising agents using various tissues or cell lines [51-55]. However, these studies have produced a wide variety of seemingly conflicting conclusions. For example, pioglitazone was shown to enhance the activation of PI 3-kinase associated with IRS-1 without changing of tyrosine phosphorylation of insulin receptor and IRS-1 [51]. Contradicting this finding, several studies reported that pioglitazone and troglitazone improve the insulin receptor tyrosine kinase defect in cultured cells induced by a high glucose concentration $[52,53]$, as well as in muscles of obese Wistar fatty rats [54]. In addition, it was reported that englitazone and oxazolidinedione CP-92, 768-2 partly prevent the down-regulation of IRS-1 in 3T3-L1 cells induced by dexamethazone [55]. In our study also, oral administration of JTT501 did not affect autophosphorylation of the insulin receptor, but did enhance the insulin stimulated activation of PI 3-kinase by increasing the protein amount and phosphorylation level of IRS-1, in adipocytes. These differences may result from differences in the cell types or the method used for inducing insulin resistance. These agents, despite being similar, may also have their own specific actions due to structural differences. Further study is necessary to clarify this issue.

Furthermore, there have been several contradictory reports concerning the effect of these agents on the regulation of GLUT4. Pioglitazone and troglitazone reportedly increase the expression of GLUT4 in muscle [56-58] and 3T3-F442 adipose cells [59], 
while it has also been shown that pioglitazone fails to correct the defect in glucose transport and its insulininduced translocation in Zucker rat skeletal muscle [60]. In addition, BRL 49653 was reported to potentiate insulin-induced glucose transport in adipocytes from insulin-resistant obese mice, both by increasing the number of insulin receptors and by facilitating GLUT4 translocation to the cell surface [61]. On the other hand, our results show clearly that JTT-501 has no effect on the regulation of GLUT4 expression, while almost completely normalising its insulin-induced translocation. We speculate that in the case of JTT-501, enhanced PI 3-kinase activation due to increased IRS-1 protein and IRS-1 phosphorylation improved GLUT4 translocation.

In addition to these direct effects mediated by PPAR- $\gamma$ or other possible target molecules in insulin-sensitive cells, or both, the secondary effect via the decreased serum lipid level may contribute to the mechanism whereby insulin resistance is reduced. In fact all or most drugs belonging to this class seem to lower serum lipid concentrations [62-64]. It is well known that insulin resistance causes hyperlipidaemia, and that hyperlipidaemia may lead to insulin resistance. It was reported that bezafibrate, widely used as an antihyperlipidemic drug, not only reduces serum triglyceride concentrations but also improves insulin sensitivity in non-obese patients with hyperglycaemia and impaired glucose tolerance [65]. Therefore, both the direct effect on insulin-sensitive cells and a secondary effect related to the decreased serum lipid concentration may play an important role in the improved insulin sensitivity produced by thiazolidionedione and its derivatives.

Judging from the dose (100 $\mathrm{mg} / \mathrm{kg}$ per day) used in this study and the Km value to PPAR- $\gamma$, JTT-501 may be considered to have a similar, but not higher, potency than troglitazone in terms of its insulin-sensitising effect. However, JTT-501 probably has a considerably greater effect than troglitazone in lowering the serum triglyceride concentration in all diabetic animal models examined. In this study, JTT-501 reduced the raised serum triglyceride level caused by high fat feeding to a level lower than that of the control rats (Table 2). Many patients with NIDDM have hyperlipidaemia, and JTT-501 may therefore be a first choice treatment for them. In addition, the improvement of hyperlipidaemia may contribute to the normalisation of the glucose concentration in humans in the long run, which should be investigated in a human study in the future.

In summary, we have shown that JTT-501 almost completely resolves the impaired insulin-induced GLUT4 translocation to the cell surface caused by feeding a high fat diet. We suggest that this effect on glucose transporter translocation is attributable to the reversed PI 3-kinase activation defect associated with an increased IRS-1 content. However, JTT-501 failed to reverse the reduction in GLUT4 expression. These results, taken with those of glucose clamp studies, suggest that JTT-501 is a promising treatment for NIDDM.

Acknowledgements. This work was supported by a Grant-inAid for Scientific Research, 08671136 (T. A.) from the Ministry of Education, Science and Culture of Japan.

\section{References}

1. Olefsky JM, Kolterman OG, Scarlett JA (1982) Insulin action and resistance in obesity and noninsulin-dependent type II diabetes mellitus. Am J Physiol 243: E15-30

2. Dohm GL, Tapscott EB, Pories WJ et al. (1988) An in vitro human muscle preparation suitable for metabolic studies. Decreased insulin stimulation of glucose transport in muscle from morbidly obese and diabetic sujects. J Clin Invest 82: 486-494

3. Taylor R (1989) Aetiology of non-insulin dependent diabetes. Br Med Bull 45: 73-91

4. DeFronzo RA, Ferrannini E (1991) Insulin resistance. A multifaceted syndrome responsible for NIDDM, obesity, hypertension, dyslipidemia, and atherosclerotic cardiovascular disease. Diabetes Care 14: 173-194

5. Saltiel AR, Olefsky JM (1996) Thiazolidinediones in the treatment of insulin resistance and type II diabetes. Diabetes 45: 1661-1669

6. Sandouk T, Reda D, Hofmann C (1993) Antidiabetic agent pioglitazone enhances adipocyte differentiation of 3T3F442A cells. Am J Physiol 264: C1600-1608

7. Szalkowski D, White-Carrington S, Berger J, Zhang B (1995) Antidiabetic thiazolidinediones block the inhibitory effect of tumor necrosis factor-alpha on differentiation, insulin-stimulated glucose uptake, and gene expression in 3T3-L1 cells. Endocrinology 136: 1474-1481

8. Cushman SW, Wardzala LJ (1980) Potential mechanism of insulin action on glucose transport in the isolated rat adipose cell. Apparent translocation of intracellular transport systems to the plasma membrane. J Biol Chem 255: 4758-4762

9. Suzuki K, Kono T (1980) Evidence that insulin causes translocation of glucose transport activity to the plasma membrane from an intracellular storage site. Proc Natl Acad Sci USA 77: 2542-2545

10. Ciaraldi TP, Kolterman OG, Scarlett JA, Kao M, Olefsky JM (1982) Role of glucose transport in the postreceptor defect of non-insulin dependent diabetes mellitus. Diabetes 31: 1016-1022

11. Kashiwagi A, Verso MA, Andrews J, Vasquez B, Reaven $G$, Foley JE (1983) In vitro insulin resistance of human adipocytes isolated from subjects with noninsulin-dependent diabetes mellitus. J Clin Invest 72: 1246-1254

12. Scarlett JA, Kolterman OG, Ciaraldi TP, Kao M, Olefsky JM (1983) Insulin treatment reverses the postreceptor defect in adipocyte 3-O-methylglucose transport in type II diabetes mellitus. J Clin Endocrinol Metab 56: 1195-1201

13. Clarke JF, Young PW, Yonezawa K, Kasuga M, Holman GD (1994) Inhibition of the translocation of GLUT1 and GLUT4 in 3T3-L1 cells by the phosphatidylinositol 3-kinase inhibitor, wortmannin. Biochemical Journal 300: 631-635

14. Sanchez-Margalet V, Goldfine ID, Vlahos CJ, Sung CK (1994) Role of phosphatidylinositol-3-kinase in insulin re- 
ceptor signaling: studies with inhibitor, LY294002. Biochem Biophys Res Commun 204: 446-452

15. Quon MJ, Chen H, Ing BL et al. (1995) Roles of 1-phosphatidylinositol 3-kinase and ras in regulating translocation of GLUT4 in transfected rat adipose cells. Mol Cel Biol 15: 5403-5411

16. Kotani K, Carozzi AJ, Sakaue H et al. (1995) Requirement for phosphoinositide 3-kinase in insulin-stimulated GLUT4 translocation in 3T3-L1 adipocytes. Biochem Biophys Res Commun 209: 343-348

17. Katagiri H, Asano T, Ishihara H et al. (1996) Overexpression of catalytic subunit p110alpha of phosphatidylinositol 3-kinase increases glucose transport activity with translocation of glucose transporters in 3T3-L1 adipocytes. J Biol Chem 271: 16987-16990

18. Martin SS, Haruta T, Morris AJ, Klippel A, Williams LT, Olefsky JM (1996) Activated phosphatidylinositol 3-kinase is sufficient to mediate actin rearrangement and GLUT4 translocation in 3T3-L1 adipocytes. J Biol Chem 271: 17605-17608

19. Saad MJ, Araki E, Miralpeix M, Rothenberg PL, White MF, Kahn CR (1992) Regulation of insulin receptor substrate-1 in liver and muscle of animal models of insulin resistance. J Clin Invest 90: 1839-1849

20. Saad MJ, Folli F, Kahn CR (1995) Insulin and dexamethasone regulate insulin receptors, insulin receptor substrate1, and phosphatidylinositol 3-kinase in Fao hepatoma cells. Endocrinology 136: 1579-1588

21. Sherman WM, Katz AL, Cutler CL, Withers RT, Ivy JL (1988) Glucose transport: locus of muscle insulin resistance in obese Zucker rats. Am J Physiol 255: E374-382

22. King PA, Horton ED, Hirshman MF, Horton ES (1992) Insulin resistance in obese Zucker rat (fa/fa) skeletal muscle is associated with a failure of glucose transporter translocation. J Clin Invest 90: 1568-1575

23. Uphues I, Kolter T, Goud B, Eckel J (1995) Failure of insulin-regulated recruitment of the glucose transporter GLUT4 in cardiac muscle of obese Zucker rats is associated with alterations of small-molecular-mass GTP-binding proteins. Biochem J 311: 161-166

24. Honnor RC, Dhillon GS, Londos C (1985) cAmp-dependent protein kinase and lipolysis in rat adipocytes. I. Cell preparation, manipulation, and predictability in behavior. J Biol Chem 260: 15122-15129

25. McKeel DW, Jarett L (1970) Preparation and characterization of a plasma membrane fraction from isolated fat cells. J Cell Biol 44: 417-432

26. Oppenheimer CL, Pessin JE, Massague J, Gitomer W, Czech MP (1983) Insulin action rapidly modulates the apparent affinity of the insulin-like growth factor II receptor. J Biol Chem 258: 4824-4830

27. Oka Y, Asano T, Shibasaki Y, Kasuga M, Kanazawa Y, Takaku F (1988) Studies with antipeptide antibody suggest the presence of at least two types of glucose transporter in rat brain and adipocyte. J Biol Chem 263: 1343213439

28. Inukai K, Funaki M, Ogihara T et al. (1997) p85 gene generates three isoforms of regulatory subunit for phosphatidylinositol 3-kinase (PI 3-kinase), p50, p55 and p85, with different PI 3-kinase activity elevating responses to insulin. J Biol Chem 272: 7873-7882

29. Olefsky JM (1975) Effect of dexamethasone on insulin binding, glucose transport, and glucose oxidation of isolated rat adipocytes. J Clin Invest 56: 1499-1508

30. Barrett-Connor E (1989) Epidemiology, obesity, and noninsulin-dependent diabetes mellitus. Epidemiol Rev 11: 172-181
31. Edelstein SL, Knowler WC, Bain RP et al. (1997) Predictors of progression from impaired glucose tolerance to NIDDM: an analysis of six prospective studies. Diabetes 46: 701-710

32. Grundleger ML, Thenen SW (1982) Decreased insulin binding, glucose transport, and glucose metabolism in soleus muscle of rats fed a high fat diet. Diabetes 31: 232-237

33. Susini C, Lavau M (1978) In-vitro and in-vivo responsiveness of muscle and adipose tissue to insulin in rats rendered obese by a high-fat diet. Diabetes 27: 114-120

34. Storlien LH, James DE, Burleigh KM, Chisholm DJ, Kraegen EW (1986) Fat feeding causes widespread in vivo insulin resistance, decreased energy expenditure, and obesity in rats. Am J Physiol 251: E576-E583

35. Fujimoto WY, Bergstrom RW, Boyko EJ et al. (1994) Diabetes and diabetes risk factors in second- and third-generation Japanese Americans in Seattle, Washington. Diabetes Res Clin Pract 24 (Suppl): S43-52

36. Cederholm J, Wibell L (1985) Glucose tolerance and physical activity in a health survey of middle-aged subjects. Acta Med Scand 217: 373-378

37. Frisch RE, Wyshak G, Albright TE, Albright NL, Schiff I (1986) Lower prevalence of diabetes in female former college athletes compared with nonathletes. Diabetes 35: 1101-1105

38. Seals DR, Hagberg JM, Allen WK et al. (1984) Glucose tolerance in young and older athletes and sedentary men. J Appl Physiol 56: 1521-1525

39. Nagy K, Levy J, Grunberger G (1990) High-fat feeding induces tissue-specific alteration in proportion of activated insulin receptors in rats. Acta Endocrinol (Copenh) 122:361-368

40. Stevenson RW, McPherson PK, Persson LM et al. (1996) The antihyperglycemic agent englitazone prevents the defect in glucose transport in rats fed a high-fat diet. Diabetes 45: 60-66

41. Kim YB, Nakajima R, Matsuo T et al. (1996) Gene expression of insulin signal-transduction pathway intermediates is lower in rats fed a beef tallow diet than in rats fed a safflower oil diet. Metabolism 45: 1080-1088

42. Pedersen O, Kahn CR, Flier JS, Kahn BB (1991) High fat feeding causes insulin resistance and a marked decrease in the expression of glucose transporters (Glut 4) in fat cells of rats. Endocrinology 129: 771-777

43. Asano T, Takata K, Katagiri H et al. (1992) Domains responsible for the differential targeting of glucose transporter isoforms. J Biol Chem 267: 19636-19641

44. Kahn BB (1996) Lilly lecture 1995. Glucose transport: pivotal step in insulin action. Diabetes 45: 1644-1654

45. Marette A, Burdett E, Douen A, Vranic M, Klip A (1992) Insulin induces the translocation of GLUT4 from a unique intracellular organelle to transverse tubules in rat skeletal muscle. Diabetes 41: 1562-1569

46. Koranyi LI, Bourey RE, Vuorinen-Markkola $\mathrm{H}$ et al. (1991) Level of skeletal muscle glucose transporter protein correlates with insulin-stimulated whole body glucose disposal in man. Diabetologia 34: 763-765

47. Lehmann JM, Moore LB, Smith-Oliver TA, Wilkison WO, Willson TM, Kliewer SA (1995) An antidiabetic thiazolidinedione is a high affinity ligand for peroxisome proliferator-activated receptor gamma (PPAR gamma). J Biol Chem 270: 12953-12956

48. Forman BM, Tontonoz P, Chen J, Brun RP, Spiegelman BM, Evans RM (1995) 15-Deoxy-delta 12, 14-prostaglandin $\mathrm{J} 2$ is a ligand for the adipocyte determination factor PPAR gamma. Cell 83: 803-812

49. Kliewer SA, Lenhard JM, Willson TM, Patel I, Morris DC, Lehmann JM (1995) A prostaglandin J2 metabolite binds 
peroxisome proliferator-activated receptor gamma and promotes adipocyte differentiation. Cell 83: 813-819

50. Lambe KG, Tugwood JD (1996) A human peroxisomeproliferator-activated receptor-gamma is activated by inducers of adipogenesis, including thiazolidinedione drugs. Eur J Biochem 239: 1-7

51. Zhang B, Szalkowski D, Diaz E, Hayes N, Smith R, Berger J (1994) Potentiation of insulin stimulation of phosphatidylinositol 3-kinase by thiazolidinedione-derived antidiabetic agents in Chinese hamster ovary cells expressing human insulin receptors and L6 myotubes. J Biol Chem 269: 25735-25741

52. Maegawa H, Tachikawa-Ide R, Ugi S et al. (1993) Pioglitazone ameliorates high glucose induced desensitization of insulin receptor kinase in rat 1 fibroblasts in culture. Biochem Biophys Res Commun 197: 1078-1082

53. Kellerer M, Kroder G, Tippmer S et al. (1994) Troglitazone prevents glucose-induced insulin resistance of insulin receptor in rat-1 fibroblasts. Diabetes 43: 447-453

54. Kobayashi M, Iwanishi M, Egawa K, Shigeta Y (1992) Pioglitazone increases insulin sensitivity by activating insulin receptor kinase. Diabetes 41: 476-483

55. Turnbow MA, Smith LK, Garner CW (1995) The oxazolidinedione CP-92, 768-2 partially protects insulin receptor substrate-1 from dexamethasone down-regulation in 3T3L1 adipocytes. Endocrinology 136: 1450-1458

56. Weinstein SP, Holand A, E OB, Haber RS (1993) Effects of thiazolidinediones on glucocorticoid-induced insulin resistance and GLUT4 glucose transporter expression in rat skeletal muscle. Metabolism 42: 1365-1369

57. Ciaraldi TP, Huber-Knudsen K, Hickman M, Olefsky JM (1995) Regulation of glucose transport in cultured muscle cells by novel hypoglycemic agents. Metabolism 44: 976-981

58. Hofmann C, Lorenz K, Colca JR (1991) Glucose transport deficiency in diabetic animals is corrected by treatment with the oral antihyperglycemic agent pioglitazone. Endocrinology 129: 1915-1925

59. Sandouk T, Reda D, Hofmann C (1993) The antidiabetic agent pioglitazone increases expression of glucose transporters in 3T3-F442A cells by increasing messenger ribonucleic acid transcript stability. Endocrinology 133: 352-359

60. Hirshman MF, Fagnant PM, Horton ED, King PA, Horton ES (1995) Pioglitazone treatment for 7 days failed to correct the defect in glucose transport and glucose transporter translocation in obese Zucker rat (fa/fa) skeletal muscle plasma membranes. Biochem Biophys Res Commun 208: 835-845

61. Young PW, Cawthorne MA, Coyle PJ et al. (1995) Repeat treatment of obese mice with BRL 49653, a new potent insulin sensitizer, enhances insulin action in white adipocytes. Association with increased insulin binding and cell-surface GLUT4 as measured by photoaffinity labeling. Diabetes 44: 1087-1092

62. Fujiwara T, Yoshioka S, Yoshioka T, Ushiyama I, Horikoshi H (1988) Characterization of new oral antidiabetic agent CS-045. Studies in KK and ob/ob mice and Zucker fatty rats. Diabetes $37: 1549-1558$

63. Kaumi T, Hirano T, Odaka H et al. (1996) VLDL triglyceride kinetics in Wistar fatty rats, an animal model of NIDDM: effects of dietary fructose alone or in combination with pioglitazone. Diabetes 45: 806-811

64. Oakes ND, Kennedy CJ, Jenkins AB, Laybutt DR, Chisholm DJ, Kraegen EW (1994) A new antidiabetic agent, BRL 49653, reduces lipid availability and improves insulin action and glucoregulation in the rat. Diabetes 43: $1203-1210$

65. Inoue I, Takahashi K, Katayama S et al. (1995) Effect of troglitazone (CS-045) and bezafibrate on glucose tolerance, liver glycogen synthase activity, and beta-oxidation in fructose-fed rats. Metabolism 44: 1626-1630 